\title{
Characterization and Evaluation of Antibacterial Activities of Chemically Synthesized Iron Oxide Nanoparticles
}

\author{
Sudhanshu Shekhar Behera ${ }^{1}$ Jayanta Kumar Patra ${ }^{1}$, Krishna Pramanik ${ }^{2}$, Niladri Panda ${ }^{2}$, \\ Hrudayanath Thatoi ${ }^{*}$ \\ ${ }^{1}$ Department of Biotechnology, College of Engineering and Technology, Biju Patnaik University of Technology, Bhubaneswar, India \\ ${ }^{2}$ Department of Biotechnology and Medical Engineering, National Institute of Technology, Rourkela, India \\ Email: ${ }^{*}$ hn_thatoi@rediffmail.com
}

Received September 11, 2012; revised October 8, 2012; accepted October 30, 2012

\begin{abstract}
The iron oxide nanoparticles have been synthesized in co-precipitation method using aqueous solution of ferric and ferrous ions with sodium salt. The synthesis of iron-oxide nanoparticles were validated by UV-Visible spectroscopy which showed higher peak at $370 \mathrm{~nm}$ as valid standard reference. An average size of iron oxide nanoparticle found by diffraction light scattering (DLS) particle size analyser, ranges approximately between $10 \mathrm{~nm}$ to $120 \mathrm{~nm}$ with mean particle size of $66 \mathrm{~nm}$. The X-ray power diffraction (XRD) analysis revealed the crystallographic structure of magnetic particles. Characterization of the mean particle size and morphology of iron oxide nanoparticles confirmed that the iron oxide nanoparticles are nearly spherical and crystalline in shape. Further the antibacterial effect of iron oxide nanoparticles was evaluated against ten pathogenic bacteria which showed that the nanoparticles have moderate antibacterial activity against both Gram positive and Gram negative pathogenic bacterial strains and retains potential application in pharmaceutical and biomedical industries.
\end{abstract}

Keywords: Iron Oxide; Co-Precipitation; Nanoparticles; Antibacterial Activity

\section{Introduction}

Nanometer-size metallic nanoparticles have been the subject to research in recent years because these materials represent an intermediate dimension between bulk materials and atoms/molecules [1]. Among these metallic nanoparticles, iron oxide (IO) have received special attention because of their variety of scientific and technological applications such as biosensor [2], antimicrobial activity [3], food preservation [4], magnetic storage media, ferrofluids, magnetic refrigeration, magnetic resonance imaging, hyperthermic cancer treatments, cell sorting and targeted drug delivery [5-7]. Besides, it has also been widely used in biomedical research because of its biocompatibility and magnetic properties [8]. The synthesis of these IO nanoparticles are carried out by differerent chemical approaches such as coprecipitation, Solgel and forced hydrolysis, hydrothermal, surfactant mediated/template synthesis, microimulsion, electrochemi$\mathrm{cal}$ and laser pyrolysis. Among these, the co-precipitation technique is probably the simplest and most efficient chemical pathway through which a larger amount of nanoparticles can be synthesized [9].

The development of new resistant strains of bacteria to

"Corresponding author. current antibiotics has become a serious problem in public health; therefore there is a strong incentive to develop new bacteriocides from various sources [10]. Recent advancement in the field of nanotechnology has provided attractive method for synthesizing alternative antimicrobial agents and reducing biofilm formation [11]. Although nanoparticles have long been known to exhibit a strong toxicity to a wide range of micro-organisms $[10$, 12], very little is known about the toxicity of iron oxide nanoparticles towards these microorganisms.

In the present study, an attempt has been made to synthesize iron-oxide nanoparticles in co-precipitation method and characterize it by absorption spectrophotometer (UVVIS), particle size analyzer (PD), X-ray diffraction (XRD), and scanning electron microscope (SEM) along with the evaluation of their antibacterial activity against ten human pathogenic Gram positive and Gram negative bacteria with a view to explore their pharmaceutical applications.

\section{Materials and Methods}

\subsection{Materials}

All the chemicals used in this work were analytical reagent grade from commercial market. Distilled water was used for preparation of the solutions after deoxygenation 
with dry $\mathrm{N}_{2}$ for $10 \mathrm{~min}$. The divalent $\left(\mathrm{FeCl}_{2} \cdot 4 \mathrm{H}_{2} \mathrm{O}\right)$, trivalent $\left(\mathrm{FeCl}_{3} \cdot 6 \mathrm{H}_{2} \mathrm{O}\right)$ iron salts, $2 \mathrm{M} \mathrm{HCl}$ solution and aqueous $\mathrm{NaOH}(25 \%-28 \%$, w/w) were also deoxygenated with dry nitrogen before use.

\subsection{Synthesis of Iron-Oxide Nanoparticles}

Iron-oxide (IO) nanoparticles were synthesized by coprecipitation method as reported by Predoi [13]. The synthesis was carried out by coprecipitation of ferrous and ferric ion salts in aqueous solution by adding base at room temperature with flowing $\mathrm{N}_{2}$ gas. Briefly, $4.0 \mathrm{ml}$ of $1 \mathrm{M} \mathrm{FeCl}_{3}$ and $1.0 \mathrm{ml}$ of $2 \mathrm{M} \mathrm{FeCl}_{2}$ solution were dissolved in deionised deoxygenated (DD) water followed by adding $200 \mathrm{ml}$ of $0.02 \mathrm{M} \mathrm{HCl}$ solution under vigorous stirring at $8000 \mathrm{rpm}$ for about $30 \mathrm{~min}$. The resulting brown precipitate was added with $200 \mathrm{ml}$ of $1.5 \mathrm{M}$ $\mathrm{NaOH}$ solution, the color of the mixture then turned from brown to black.

$$
2 \mathrm{Fe}^{3+}+\mathrm{Fe}^{2+}+8 \mathrm{OH}^{-} \rightarrow \mathrm{Fe}_{3} \mathrm{O}_{4} \downarrow+4 \mathrm{H}_{2} \mathrm{O}
$$

The $\mathrm{Fe}_{3} \mathrm{O}_{4}$ (IO) nanoparticles were finally collected as power after oven dried at $50^{\circ} \mathrm{C}$ (Figure 1).

\subsection{Characterization Techniques}

\subsubsection{UV-VIS Spectra Analysis (UV-VIS)}

The reduction of pure $\mathrm{Fe}^{3+}$ ions was monitored by measuring the UV-VIS spectrum of the reaction medium after diluting a small aliquot of the sample into distilled water at wave length 330 - $450 \mathrm{~nm}$. UV-VIS spectral analysis was done by using UV-VIS spectrophotometer (Systronis-117).

\subsubsection{Particle Size Analysis (PD)}

In order to determine the average particle size distribution, the milled powder of iron oxide nanoparticles was measured by ZETA Sizer Nanoseries (Malvern instruments Nano ZS). Initially, the liquid dispersant containing $500 \mathrm{ml}$ of deionized water and $25 \mathrm{ml}$ of sodium hexametaphosphate was kept in the sample holder and then iron oxide (IO) nanoparticles were dispersed in deionised water followed by ultrasonication.

\subsubsection{X-Ray Diffraction (XRD)}

In order to obtain the structural information of the pro-

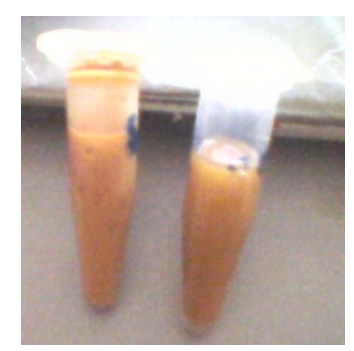

Figure 1. Synthesized ironoxide nanoparticles. duct, the crystallographic structure of magnetic particles was analyzed by X-ray power diffraction (XRD). The crystallographic analysis of samples in diffraction patterns were recorded from $10^{\circ}$ to $70^{\circ}$ with a panalytical system diffractometer (Model: DY-1656) using $\mathrm{Cu} \mathrm{K} \alpha(\lambda$ $=1.542 \mathrm{Ao})$ with an accelerating voltage of $40 \mathrm{KV}$. Data were collected with a counting rate of $1 \% \mathrm{~min}$. The $\mathrm{K} \alpha$ doublets were well resolved.

\subsubsection{Scanning Electron Microscope (SEM)}

To characterize mean particle size and morphology of Iron oxide nanoparticles, SEM (scanning electron microscope) was performed using Jeol JSM-6480 LV SEM machine of $20 \mathrm{KV}$ of accelerating voltage.

\subsubsection{Screening of Antimicrobial Activity}

Ten pathogenic bacteria viz. Staphylococcus aureus (MTCC 1144), Shigella flexneri (Lab isolate), Bacillus licheniformis (MTCC 7425), Bacillus brevis (MTCC 7404), Vibrio cholerae (MTCC 3904), Pseudomonas aeruginosa (MTCC 1034), Streptococcus aureus (Lab isolate), Staphylococcus epidermidis (MTCC 3615), Bacillus subtilis (MTCC 7164) and E. coli (MTCC 1089) used in the study were obtained from Institute of Microbial Technology, Chandigarh or lab isolates. The organisms were maintained on nutrient agar (Hi Media, India) slopes at $4^{\circ} \mathrm{C}$ and subcultured before use.

Agar cup plate method of Khalid et al. [14] was carried out to establish the antibacterial activity of the iron oxide (IO) nanoparticles against the test pathogens. Wells of $6 \mathrm{~mm}$ diameter were punched over the agar plates using sterile gel puncher (cork borer) $100 \mu \mathrm{l}$ (50 $\mathrm{mg} / \mathrm{ml}$ ) of nanoparticle powder in sterile distilled water were poured into the wells. The plates were incubated at $37^{\circ} \mathrm{C}$ for $24 \mathrm{~h}$. The zone of the clearance around each well after the incubation period, confirms the antimicrobial activity of the IO nanoparticle extract. Neomycin (30 $\mu \mathrm{g} / \mathrm{disc}$ ) was taken as standard.

\section{Results and Discussion}

The iron oxide nanoparticles $\left(\mathrm{Fe}_{3} \mathrm{O}_{4}\right)$ synthesized by coprecipitation of ferric and ferrous chloride was validated by UV-Visible spectroscopic analysis and their scanning absorbance vs wave length $(\lambda)$ has been established (Figure 2). The characteristics peaks of IO nanoparticles were observed at $370 \mathrm{~nm}$, which is due to charge transfer spectra. The particle size distribution of the iron oxide nanoparticles determined by laser diffraction method with a multiple scattering technique revealed that the particle size distribution of iron oxide nanoparticles ranges approximately from $10 \mathrm{~nm}$ to $120 \mathrm{~nm}$ with mean particle size of $66 \mathrm{~nm}$ and the distribution of oxide nanoparticle is more uniform with a narrow distribution range (Figure 3). 
The XRD analysis of IO nanoparticles shown in Figure 4, were made to detect the diffraction angles at $31.5^{\circ}$, $35^{\circ}, 37^{\circ}, 45.2^{\circ}$ and $53^{\circ}$ which implies the diffraction surfaces of the nanoparticle crystal. The diffraction angles of different peaks are corresponds to $\mathrm{Fe}_{3} \mathrm{O}_{4}$ nanoparticles.

This data is very close to the American Society for Testing and Materials (ASTM) data of iron oxide $\left[\left(\mathrm{Fe}_{3} \mathrm{O}_{4}\right)\right]$ nanoparticles, which could be a good evidence to prove that the prepared nanoparticles, was made of iron oxide. The X-ray power diffraction (XRD) results of nanoparticles confirmed that the synthesized product was a magnetite $\left(\mathrm{Fe}_{3} \mathrm{O}_{4}\right)$ [15].

Further analysis of the SEM image of synthesized iron oxide nanoparticles, showed a clear image of highly dense IO nanoparticles which are almost spherical in size (Figure 5). The size of most of the nanoparticles ranges from $30 \mathrm{~nm}$ to $110 \mathrm{~nm}$. However the percentage of nanoparticles beyond $100 \mathrm{~nm}$ is very less. The average percentage of nanoparticles present in our synthesized

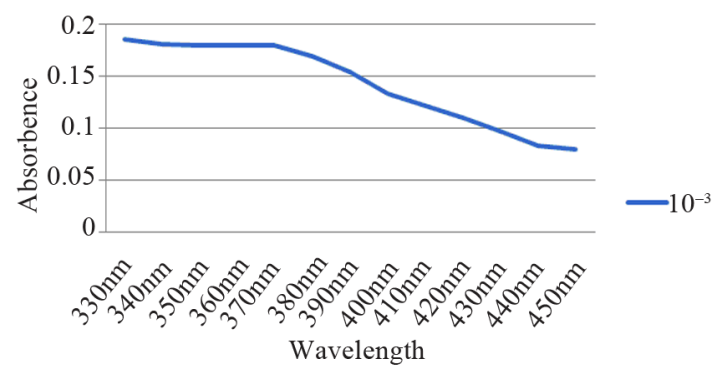

Figure 2. The UV-VIS spectrum of $\mathrm{Fe}_{3} \mathrm{O}_{4}$ naoparticles.

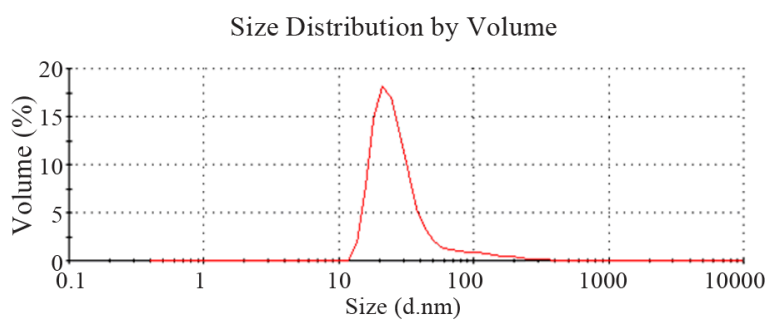

Figure 3. DLS particle size analysis curve of iron oxide nanoparticles.

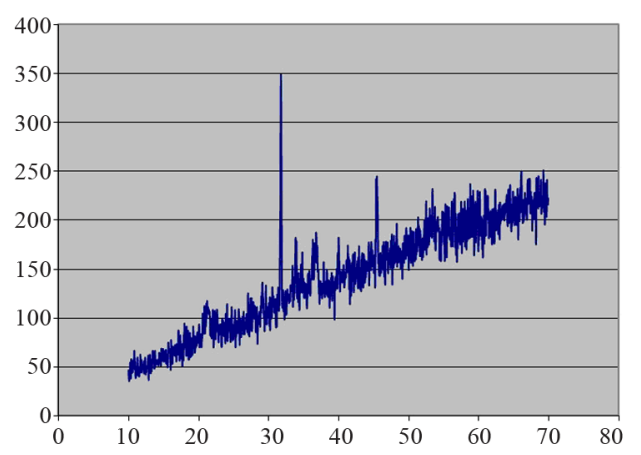

Figure 4. XRD of $\mathrm{Fe}_{3} \mathrm{O}_{4}$ nanoparticles. sample is $66 \mathrm{~nm}$. From the image it is confirmed that the sample contains various sizes of nanoparticles which are indeed agreement with the result obtained from DLS particle analyser. Similar results on SEM analysis of IO nanoparticles has also been reported by other workers [7].

The antibacterial activities of the iron oxide nanoparticle evaluated against ten pathogenic bacteria (six Gram positive and four Gram negative) are presented in (Table 1 and Figure 6). The result of antibacterial activity of IO nanoparticle showed moderate antimicrobial activity against eight pathogenic strains (six gram positive and two gram negative) with zone of inhibition ranging from 9 $\mathrm{mm}$ to $22 \mathrm{~mm}$ (Table 1).

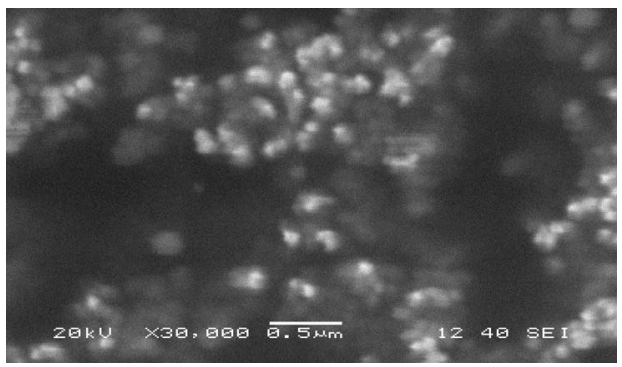

Figure 5. SEM image of synthesized iron oxide nanoparticles.

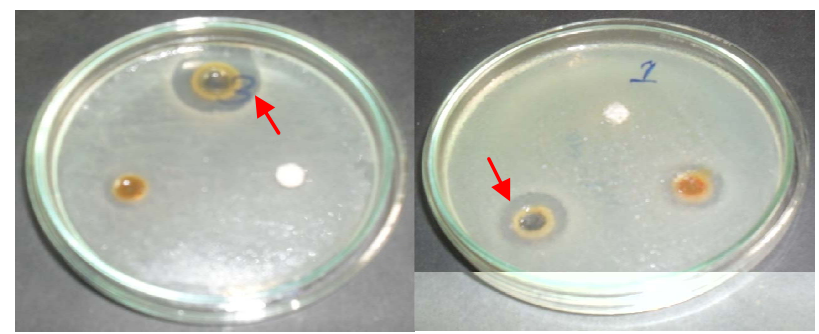

Figure 6. Study of antibacterial activity (zone of inhibition) of $\mathrm{Fe}_{3} \mathrm{O}_{4}$ nanoparticles.

Table 1. Antibacterial activity of iron oxide nanoparticle and standard antibiotics.

\begin{tabular}{ccc}
\hline Strains & $\begin{array}{c}\text { Iron oxide } \\
\text { nanoparticles }(50 \mathrm{mg} / \mathrm{ml})\end{array}$ & $\begin{array}{c}\text { Standard antibiotics } \\
\text { neomycin }(30 \mu \mathrm{g} / \mathrm{disc})\end{array}$ \\
\hline Staphylococcus aureus & $12 \pm 0.35$ & $17 \pm 0.70$ \\
Shigella flexneri & $0 \pm 0.0$ & $18 \pm 0.35$ \\
Bacillus licheniformis & $22 \pm 0.70$ & $21 \pm 1.4$ \\
Bacillus brevis & $9 \pm 0.15$ & $27 \pm 0.35$ \\
$\begin{array}{c}\text { Vibrio cholerae } \\
\text { Pseudomonas } \\
\text { aeruginosa }\end{array}$ & $9 \pm 0.0$ & $18 \pm 0.70$ \\
Streptococcus aureus & $12 \pm 0.35$ & $18 \pm 0.35$ \\
Staphylococcus \\
epidermidis
\end{tabular}


The present results are comparable with that of the standard antibiotic Neomycin $(30 \mu \mathrm{g} / \mathrm{disc})$. The IO nanoparticles do not show any activity against two Gram negative bacteria viz. Shigella flexneri and Pseudomonas aeruginosa (Table 1). There are many factors responsible for the antibacterial activity of iron oxide nanoparticles.

The main mechanism by which these particles showed antibacterial activity might be via oxidative stress generated by ROS [10,12]. ROS, including superoxide radicals $\left(\mathrm{O}^{2-}\right)$, hydroxyl radicals $(-\mathrm{OH})$, hydrogen peroxide $\left(\mathrm{H}_{2} \mathrm{O}_{2}\right)$, and singlet oxygen $\left({ }^{1} \mathrm{O}_{2}\right)$, can cause damage to proteins and DNA in bacteria. In the present study, metal oxide $(\mathrm{FeO})$ could be the source that created ROS leading to the inhibition of most of the pathogenic bacteria including Staphylococcus aureus. A similar process was also described by Kim et al. (2007) in which $\mathrm{Fe}^{2+}$ reacted with oxygen to create hydrogen peroxide $\left(\mathrm{H}_{2} \mathrm{O}_{2}\right)$. This $\mathrm{H}_{2} \mathrm{O}_{2}$ consequently reacted with ferrous irons via the Fenton reaction and produced hydroxyl radicals which are known to damage biological macromolecules [16].

Some authors have demonstrated that the small size of nanoparticles can also contribute to bactericidal effects. For example, Lee et al. [17] reported that the inactivation of Escherichia coli by zero-valent iron nanoparticles [17] could be because of the penetration of the small particles (sizes ranging from $10-80 \mathrm{~nm}$ ) into E. coli membranes. Nano scale zero valent iron (NZVI) could then react with intracellular oxygen, leading to oxidative stress and eventually causing disruption of the cell membrane. Studies on $\mathrm{ZnO}$ and $\mathrm{MgO}$ nanoparticles have also shown that antibacterial activity increased with decreasing particle size $[18,19]$. In the present study, the concentration of nanoparticles was a major factor for antibacterial activity of the nanoparticle. A similar concentration-dependent behavior was observed by Kim et al. [20] when they investigated the antimicrobial effects of $\mathrm{Ag}$ and $\mathrm{ZnO}$ nanoparticles on $S$. aureus and E. coli $[18,19]$. Similarly, in a study of bactericidal effects of iron noxide nanoparticles on $S$. epidermidis, Taylor and Webster [21], also reported concentration dependent bacterial inhibition. It is also important to note that IO nanoparticles do not negatively influence all cells and thus it can be said that with an appropriate external magnetic field, FeO nanoparticles may be directed to kill bacteria as needed throughout the body.

\section{Conclusion}

Application of Iron Oxide nanoparticle shows zone of inhibition comparable to that of other nanoparticle (Ag) of topical use. Furthermore it shows better bactericidal activity in Gram-positive bacteria as compared to Gramnegative bacteria. The present study highlights the poten- tial application of IO nanoparticles as antibacterial agents which can be explored for its topical application in pharmaceutical and biomedical industries and opens the path for further research regarding the toxicity and carcinogenicity properties for its use in human being.

\section{Acknowledgements}

Authors are grateful to the authorities of NIT, Rourkela and College of Engineering and Technology, Bhubaneswar for providing laboratory facilities.

\section{REFERENCES}

[1] S. Eiglesias, J. Rivas, L. M. Leon Isidro and M. A. LopezQuintela, "Synthesis of Silver-Coated Magnetic Nanoparticles," Journal of Non-Crystal Solids, Vol. 353, No. 8-10, 2007, pp. 829-831.

[2] C. C. Berry and A. S. G. Curtis, "Functionalisation of Magnetic Nanoparticles for Applications in Biomedicine," Journal of Physics D: Applied Physics, Vol. 36, No. 13, 2003, pp. 198-206. doi:10.1088/0022-3727/36/13/203

[3] L. Babes, B. Denizot, G. Tanguy, J. J. Le Jeune and P. Jallet, "Synthesis of Iron Oxide Nanoparticles Used as MRI Contrast Agents: A Parametric Study," Journal of Colloid and Interface Science, Vol. 212, No. 2, 1999, pp. 474-482. doi:10.1006/jcis.1998.6053

[4] D. C. F. Chan, D. B. Kirpotin and P. A. Bunn, "Synthesis and Evaluation of Colloidal Magnetic Iron Oxides for the Site-Specific Radio Frequency Induced Hyperthermia of Cancer," Journal of Magnetism and Magnetic Materials, Vol. 122, No. 1, 1993, pp. 374-378. doi:10.1016/0304-8853(93)91113-L

[5] R. G. H. Beets-Tan, J. M. A. Van Engelshoven and J. W. M. Greve, "Hepatic Adenoma and Focal Nodular Hyperplasia: MR Findings with Superparamagnetic Iron Oxideenhanced MRI," Clinical Imaging, Vol. 22, No. 3, 1998, pp. 211-215. doi:10.1016/S0899-7071(97)00117-4

[6] A. K. Gupta and M. Gupta, "Synthesis and Surface Engineering of Iron Oxide Nanoparticles for Biomedical Applications," Biomaterials, Vol. 26, No. 18, 2005, pp. 39954021. doi:10.1016/j.biomaterials.2004.10.012

[7] H. Lida, K. Takayanagi, T. Nakanishi and T. Osaka, "Synthesis of $\mathrm{Fe}_{3} \mathrm{O}_{4}$ Nanoparticles with Various Sizes and Magnetic Properties by Controlled Hydrolysis," Journal of Colloid and Interface Science, Vol. 314, No. 1, 2007 , pp. 274-280. doi:10.1016/j.jcis.2007.05.047

[8] L. J. Matheson and P. G. Tratnyek, "Reductive Dehalogenation of Chlorinated Methanes by Iron Metal," Environmental Science \& Technology, Vol. 28, No. 12, 1994, pp. 2045-2053. doi:10.1021/es00061a012

[9] K. Yao, Z. Peng and X. Fan, "Preparation of Nanoparticles with an Environmental-Friendly Approach," Journal of Environmental Sciences, Vol. 21, No. 6, 2009, pp. 727-730. doi:10.1016/S1001-0742(08)62331-1

[10] S. A. Mahdy, Q. J. Raheed and P. T. Kalaichelvan, "Antimicrobial Activity of Zero-Valent Iron Nanoparticles," International Journal of Modern Engineering Research, 
Vol. 2, No. 1, 2012, pp. 578-581.

[11] M. Mohapatra and S. Anand, "Synthesis and Application of Nano-Structured Iron Oxide/Hydroxides-A Review," International Journal of Engineering and Technology, Vol. 2, No. 8, 2010, pp. 127-146.

[12] N. Tran, A. Mir, D. Mallik, A. Sinha, S. Nayar and T. J. Webster, "Bactericidal Effect of Iron Oxide Nanoparticles on Staphylococcus aureus," International Journal of Nanomedicine, Vol. 5, No. 1, 2010, pp. 277-283.

[13] D. Predoi, "A Study on Iron Oxide Nanoparticles Coated with Dextrin Obtained by Coprecipitation," Digest Journal of Nanomaterials and Biostructures, Vol. 2, No. 1, 2007, pp. 169-173.

[14] F. Khalid, R. Siddiqi and N. Mojgani, "Detection and Characterization of a Heat Stable Bacteriocin (Lactocin LC-09) Produced by a Clinical Isolate of Lactobacilli," Medical Journal of Islamic Academy of Science, Vol. 12, No. 3, 1999, pp. 67-71.

[15] X. R. Ye, C. Daraio, C. Wang, J. B. Talbot and S. Jin, "Room Temperature Solvent-Free Synthesis of Monodisperse Magnetite Nanocrystals," Journal of Nanoscience and Nanotechnology, Vol. 6, No. 3, 2006, pp. 852-856. doi:10.1166/jnn.2006.135

[16] D. Touati, "Iron and Oxidative Stress in Bacteria," Archives of Biochemistry and Biophysics, Vol. 373, No. 6,
2000, pp. 1-6. doi:10.1006/abbi.1999.1518

[17] C. Lee, J. Y. Kim, W. I. Lee, K. L. Nelson, J. Yoon and D. L. Sedlak, "Bactericidal Effect of Zero-Valent Iron Nanoparticles on Escherichia coli," Environmental Science \& Technology, Vol. 42, No. 13, 2008, pp. 4927-4933. doi:10.1021/es800408u

[18] S. Makhluf, R. Dror, Y. Nitzan, Y. Abramovich, R. Jelinek and A. Gedanken, "Microwave-Assisted Synthesis of Nanocrystalline $\mathrm{MgO}$ and Its Use as a Bacteriocide," Advanced Functional Materials, Vol. 15, No. 10, 2005, pp. 1708-1715. doi:10.1002/adfm.200500029

[19] L. Zhang, Y. Jiang, Y. Ding, M. Povey and D. York, "Investigation into the Antibacterial Behaviour of Suspensions of $\mathrm{ZnO}$ Nanoparticles (ZnO Nanofluids)," Journal of Nanoparticle Research, Vol. 9, No. 3, 2007, pp. 479489. doi:10.1007/s11051-006-9150-1

[20] J. S. Kim, E. Kuk and K. N. Yu, "Antimicrobial Effects of Silver Nanoparticles," Nanomedicine: Nanotechnology, Biology and Medicine, Vol. 3, No. 1, 2007, pp. 95-101. doi:10.1016/j.nano.2006.12.001

[21] E. N. Taylor and T. J. Webster, "The Use of Superparamagnetic Nanoparticles for Prosthetic Biofilm," International Journal of Nanomedicine, Vol. 4, No. 1, 2009, pp. 145-152. 